\title{
Approximations for Equilibrium Problems and Nonexpansive Semigroups
}

\author{
Huan-chun Wu and Cao-zong Cheng \\ Department of Mathematics, Beijing University of Technology, Beijing 100124, China \\ Correspondence should be addressed to Huan-chun Wu; wuhuanchun@emails.bjut.edu.cn
}

Received 29 November 2013; Accepted 4 February 2014; Published 16 March 2014

Academic Editor: Hassen Aydi

Copyright (C) 2014 H.-c. Wu and C.-z. Cheng. This is an open access article distributed under the Creative Commons Attribution License, which permits unrestricted use, distribution, and reproduction in any medium, provided the original work is properly cited.

We introduce a new iterative method for finding a common element of the set of solutions of an equilibrium problem and the set of all common fixed points of a nonexpansive semigroup and prove the strong convergence theorem in Hilbert spaces. Our result extends the recent result of Zegeye and Shahzad (2013). In the last part of the paper, by the way, we point out that there is a slight flaw in the proof of the main result in Shehu's paper (2012) and perfect the proof.

\section{Introduction}

Let $H$ be a real Hilbert space, and let $C$ be a nonempty closed convex subset of $H$. A mapping $T: C \rightarrow C$ is called nonexpansive if $\|T x-T y\| \leq\|x-y\|$ for all $x, y \in C$. We denote the set of fixed points of $T$ by $F(T)$. It is known that $F(T)$ is closed and convex. A family $\mathcal{S}=\{T(t): 0 \leq t<$ $\infty$ \} of mappings from $C$ into itself is called a nonexpansive semigroup on $C$ if it satisfies the following conditions:

(i) $T(0) x=x$ for all $x \in C$;

(ii) $T(s+t)=T(s) T(t)$ for all $s, t \geq 0$;

(iii) $\|T(s) x-T(s) y\| \leq\|x-y\|$ for all $x, y \in C$ and $s \geq 0$;

(iv) for all $x \in C, s \mapsto T(s) x$ is continuous.

We denote by $F(\mathcal{S})$ the set of all common fixed points of $\delta$; that is, $F(\mathcal{S})=\bigcap_{0 \leq t<\infty} F(T(t))$. It is clear that $F(\mathcal{S})$ is a closed convex subset.

The equilibrium problem for $f: C \times C \rightarrow \mathbb{R}$ is to find $\bar{x} \in C$ such that $f(\bar{x}, y) \geq 0$ for all $y \in C$. The set of such solutions is denoted by $\operatorname{EP}(f)$. Numerous problems in physics, optimization, and economics can be reduced to find a solution of the equilibrium problem (for instance, see [1]).

For solving equilibrium problem, we assume that the bifunction $f$ satisfies the following conditions:

(A1) $f(x, x)=0$ for all $x \in C$;
(A2) $f$ is monotone; that is, $f(x, y)+f(y, x) \leq 0$ for any $x, y \in C$;

(A3) for each $x, y, z \in C, \lim \sup _{t \downarrow 0} f(t z+(1-t) x, y) \leq$ $f(x, y)$

(A4) $f(x, \cdot)$ is convex and lower semicontinuous for each $x \in C$.

Several methods have been proposed to solve the equilibrium problem; see [1-7]. For finding common fixed points of a nonexpansive semigroup, Nakajo and Takahashi [8] introduced a convergent sequence for nonexpansive semigroup $\mathcal{S}=\{T(t): 0 \leq t<\infty\}$ as follows:

$$
\begin{gathered}
x_{0}=x \in C, \\
y_{n}=\alpha_{n} x_{n}+\left(1-\alpha_{n}\right) \frac{1}{t_{n}} \int_{0}^{t_{n}} T(s) x_{n} d s, \\
C_{n}=\left\{z \in C:\left\|y_{n}-z\right\| \leq\left\|x_{n}-z\right\|\right\}, \\
Q_{n}=\left\{z \in C:\left\langle x_{n}-z, x_{0}-x_{n}\right\rangle \geq 0\right\}, \\
x_{n+1}=P_{C_{n} \cap Q_{n}}\left(x_{0}\right) .
\end{gathered}
$$

Some authors have paid more attention to find an element $p \in F(\mathcal{S}) \cap \mathrm{EP}(f)$. Buong and Duong [9] constructed the following iterative sequence and proved the weak convergence 
theorem for an equilibrium problem and a nonexpansive semigroup in Hilbert spaces:

$$
\begin{gathered}
x_{0} \in H, \\
u_{k} \in C, \quad f\left(u_{k}, y\right)+\frac{1}{r_{k}}\left\langle y-u_{k}, u_{k}-x_{k}\right\rangle \geq 0 \quad \forall y \in C, \\
x_{k+1}=\mu_{k} x_{k}+\left(1-\mu_{k}\right) \frac{1}{t_{k}} \int_{0}^{t_{k}} T(s) u_{k} d s .
\end{gathered}
$$

In 2012, Shehu [10] studied iterative methods for fixed point problem, variational inequality, and generalized mixed equilibrium problem and introduced a new algorithm which does not involve the CQ algorithm and viscosity approximation method. However, we discover that there is a slight flaw in the proof of Theorem 3.1 in [10].

Motivated by Nakajo and Takahashi [8], Buong and Duong [9], and especially Shehu [10] and Zegeye and Shahzad [11], we present a new iterative method for finding a common element of the set of solutions of an equilibrium problem and the set of all common fixed points of a nonexpansive semigroup and prove the strong convergence theorem in Hilbert spaces. Our result extends the recent result of [11]. In the last part of the paper, we perfect and simplify the proof of Theorem 3.1 in [10].

\section{Preliminaries}

Throughout this paper, let $H$ be a real Hilbert space with inner product $\langle\cdot, \cdot\rangle$ and norm $\|\cdot\|$, and let $C$ be a nonempty closed convex subset of $H$. We write $x_{n} \rightarrow x$ to indicate that the sequence $\left\{x_{n}\right\}$ converges strongly to $x$. Similarly, $x_{n} \rightarrow x$ will symbolize weak convergence. It is well known that $H$ satisfies Opial's condition; that is, for any sequence $\left\{x_{n}\right\} \subset H$ with $x_{n} \rightarrow x$, we have

$$
\liminf _{n \rightarrow \infty}\left\|x_{n}-x\right\|<\liminf _{n \rightarrow \infty}\left\|x_{n}-y\right\|, \quad \forall y \neq x .
$$

For any $x \in H$, there exists a unique point $P_{C} x \in C$ such that

$$
\left\|x-P_{C} x\right\| \leq\|x-y\|, \quad \forall y \in C .
$$

$P_{C}$ is called the metric projection of $H$ onto $C$. We know that $P_{C}$ is a nonexpansive mapping of $H$ onto $C$ and $P_{C}$ satisfies

$$
\left\langle x-y, P_{C} x-P_{C} y\right\rangle \geq\left\|P_{C} x-P_{C} y\right\|^{2}, \quad \forall x, y \in H .
$$

For $x \in H$ and $z \in C$, we have

$$
z=P_{C} x \Longleftrightarrow\langle x-z, y-z\rangle \leq 0 \text {, for every } y \in C .
$$

The following lemmas will be used in the proof of our results.

Lemma 1 (see [1]). Let $C$ be a nonempty closed convex subset of $H$, and let $f$ be a bifunction from $C \times C$ to $\mathbb{R}$ satisfying (A1)(A4). If $r>0$ and $x \in H$, then there exists $z \in C$ such that

$$
f(z, y)+\frac{1}{r}\langle y-z, z-x\rangle \geq 0, \quad \forall y \in C .
$$

Lemma 2 (see [2]). For $r>0$, define a mapping $T_{r}: H \rightarrow 2^{C}$ as follows:

$$
T_{r}(x)=\left\{z \in C: f(z, y)+\frac{1}{r}\langle y-z, z-x\rangle \geq 0, \forall y \in C\right\} .
$$

Then the following hold:

(i) $T_{r}$ is single valued;

(ii) $T_{r}$ is firmly nonexpansive; that is, for any $x, y \in H$, $\left\langle x-y, T_{r} x-T_{r} y\right\rangle \geq\left\|T_{r} x-T_{r} y\right\|^{2} ;$

(iii) $F\left(T_{r}\right)=E P(f)$;

(iv) $E P(f)$ is closed and convex.

Lemma 3 (see [12]). Suppose that (A1)-(A4) hold. If $x, y \in H$ and $r_{1}, r_{2}>0$, then

$$
\left\|T_{r_{2}} y-T_{r_{1}} x\right\| \leq\|y-x\|+\frac{\left|r_{2}-r_{1}\right|}{r_{2}}\left\|T_{r_{2}} y-y\right\| .
$$

Lemma 4 (see [13]). Let $C$ be a nonempty bounded closed subset of $H$, and let $\{T(s): 0 \leq s<\infty\}$ be a nonexpansive semigroup on $C$. Then, for every $h \geq 0$,

$$
\lim _{t \rightarrow+\infty} \sup _{x \in C}\left\|\frac{1}{t} \int_{0}^{t} T(s) x d s-T(h) \frac{1}{t} \int_{0}^{t} T(s) x d s\right\|=0 .
$$

Lemma 5 (see [14]). Let $\left\{x_{n}\right\}$ and $\left\{y_{n}\right\}$ be bounded sequences in a Banach space $X$, and let $\left\{\beta_{n}\right\}$ be a sequence in $[0,1]$ with $0<\liminf _{n \rightarrow \infty} \beta_{n} \leq \limsup _{n \rightarrow \infty} \beta_{n}<1$. Suppose that $x_{n+1}=\left(1-\beta_{n}\right) x_{n}+\beta_{n} y_{n}$ for all integers $n \geq 1$ and $\lim \sup _{n \rightarrow \infty}\left(\left\|y_{n+1}-y_{n}\right\|-\left\|x_{n+1}-x_{n}\right\|\right) \leq 0$. Then, $\lim _{n \rightarrow \infty}\left\|y_{n}-x_{n}\right\|=0$.

Lemma 6 (see [15]). Let $\left\{a_{n}\right\}$ be a sequence of nonnegative real numbers satisfying $a_{n+1} \leq\left(1-\alpha_{n}\right) a_{n}+\alpha_{n} \beta_{n}$, where

(i) $\left\{\alpha_{n}\right\} \subset(0,1), \sum_{n=1}^{\infty} \alpha_{n}=\infty$;

(ii) $\limsup _{n \rightarrow \infty} \beta_{n} \leq 0$.

Then, $\lim _{n \rightarrow \infty} a_{n}=0$.

\section{Strong Convergence Theorems}

In this section, we introduce a new iterative method for finding a common element of the set of solutions of an equilibrium problem and the set of all common fixed points of a nonexpansive semigroup and prove the strong convergence theorem in Hilbert spaces.

Theorem 7. Let $C$ be a nonempty closed convex subset of a real Hilbert space $H$, and let $f$ be a bifunction from $C \times C$ to $\mathbb{R}$ satisfying (A1)-(A4). Suppose that $\mathcal{S}=\{T(t): 0 \leq t<\infty\}$ 
is a nonexpansive semigroup on $C$ such that $F(\mathcal{S}) \cap E P(f) \neq \emptyset$. For $u \in H$, let $\left\{x_{n}\right\},\left\{y_{n}\right\}$, and $\left\{z_{n}\right\}$ be generated by

$$
\begin{gathered}
x_{1} \in C \text { chosen arbitrarily, } \\
y_{n}=\alpha_{n} u+\left(1-\alpha_{n}\right) x_{n}, \\
z_{n} \in C \text {, such that } f\left(z_{n}, y\right)+\frac{1}{r_{n}}\left\langle y-z_{n}, z_{n}-y_{n}\right\rangle \geq 0 \\
\quad \forall y \in C, \\
x_{n+1}=\left(1-\beta_{n}\right) x_{n}+\beta_{n} \frac{1}{t_{n}} \int_{0}^{t_{n}} T(s) z_{n} d s,
\end{gathered}
$$

where the real sequences $\left\{\alpha_{n}\right\},\left\{\beta_{n}\right\}$ in $(0,1)$ and $\left\{r_{n}\right\} \subset(0, \infty)$ satisfy the following conditions:

(1) $\lim _{n \rightarrow \infty} \alpha_{n}=0$ and $\sum_{n=1}^{\infty} \alpha_{n}=\infty$;

(2) $0<\liminf _{n \rightarrow \infty} \beta_{n} \leq \lim \sup _{n \rightarrow \infty} \beta_{n}<1$;

(3) $0<c \leq r_{n}<\infty, \lim _{n \rightarrow \infty}\left|r_{n+1}-r_{n}\right|=0$;

(4) $\left\{t_{n}\right\} \subset(0, \infty), \lim _{n \rightarrow \infty} t_{n}=\infty$ and $\lim _{n \rightarrow \infty}\left(\mid t_{n+1}-\right.$ $\left.t_{n} \mid / t_{n+1}\right)=0$.

Then, the sequence $\left\{x_{n}\right\}$ converges strongly to $P_{F(\delta) \cap E P(f)} u$.

Proof. Note that the set $F(\mathcal{S}) \cap \mathrm{EP}(f)$ is closed and convex since $F(\mathcal{S})$ and $\operatorname{EP}(f)$ are closed and convex. For simplicity, we write $\Omega:=F(\mathcal{S}) \cap \operatorname{EP}(f)$. $p \in \Omega$,

From Lemmas 1 and 2, we have $z_{n}=T_{r_{n}} y_{n}$, and, for any

$$
\left\|z_{n}-p\right\|=\left\|T_{r_{n}} y_{n}-T_{r_{n}} p\right\| \leq\left\|y_{n}-p\right\| .
$$

Observe that

$$
\left\|y_{n}-p\right\| \leq \alpha_{n}\|u-p\|+\left(1-\alpha_{n}\right)\left\|x_{n}-p\right\|
$$

It follows that

$$
\begin{aligned}
\left\|x_{n+1}-p\right\|= & \left\|\left(1-\beta_{n}\right) x_{n}+\beta_{n} \frac{1}{t_{n}} \int_{0}^{t_{n}} T(s) z_{n} d s-p\right\| \\
\leq & \left(1-\beta_{n}\right)\left\|x_{n}-p\right\| \\
& +\beta_{n} \frac{1}{t_{n}} \int_{0}^{t_{n}}\left\|T(s) z_{n}-T(s) p\right\| d s \\
\leq & \left(1-\beta_{n}\right)\left\|x_{n}-p\right\|+\beta_{n}\left\|z_{n}-p\right\| \\
\leq & \left(1-\beta_{n}\right)\left\|x_{n}-p\right\| \\
& +\beta_{n}\left[\alpha_{n}\|u-p\|+\left(1-\alpha_{n}\right)\left\|x_{n}-p\right\|\right] \\
\leq & \left(1-\alpha_{n} \beta_{n}\right)\left\|x_{n}-p\right\|+\alpha_{n} \beta_{n}\|u-p\| \\
\leq & \max \left\{\left\|x_{n}-p\right\|,\|u-p\|\right\} .
\end{aligned}
$$

From a simple inductive process, one has

$$
\left\|x_{n+1}-p\right\| \leq \max \left\{\left\|x_{1}-p\right\|,\|u-p\|\right\},
$$

which yields that $\left\{x_{n}\right\}$ is bounded. So are $\left\{y_{n}\right\}$ and $\left\{z_{n}\right\}$.

Set $\sigma_{n}=\left(1 / t_{n}\right) \int_{0}^{t_{n}} T(s) z_{n} d s$. For any $p \in \Omega$, we have

$$
\begin{aligned}
\| \sigma_{n+1}- & \sigma_{n} \| \\
= & \left\|\frac{1}{t_{n+1}} \int_{0}^{t_{n+1}} T(s) z_{n+1} d s-\frac{1}{t_{n}} \int_{0}^{t_{n}} T(s) z_{n} d s\right\| \\
= & \| \frac{1}{t_{n+1}} \int_{0}^{t_{n+1}} T(s) z_{n+1} d s-\frac{1}{t_{n+1}} \int_{0}^{t_{n+1}} T(s) z_{n} d s \\
& +\frac{1}{t_{n+1}} \int_{0}^{t_{n+1}} T(s) z_{n} d s-\frac{1}{t_{n}} \int_{0}^{t_{n}} T(s) z_{n} d s \| \\
= & \| \frac{1}{t_{n+1}} \int_{0}^{t_{n+1}}\left(T(s) z_{n+1}-T(s) z_{n}\right) d s \\
& +\left(\frac{1}{t_{n+1}}-\frac{1}{t_{n}}\right) \int_{0}^{t_{n}} T(s) z_{n} d s+\frac{1}{t_{n+1}} \int_{t_{n}}^{t_{n+1}} T(s) z_{n} d s \| \\
= & \| \frac{1}{t_{n+1}} \int_{0}^{t_{n+1}}\left(T(s) z_{n+1}-T(s) z_{n}\right) d s \\
& +\left(\frac{1}{t_{n+1}}-\frac{1}{t_{n}}\right) \int_{0}^{t_{n}}\left(T(s) z_{n}-T(s) p\right) d s \\
& +\left(\frac{1}{t_{n+1}}-\frac{1}{t_{n}}\right) \int_{0}^{t_{n+1}} T(s) p d s+\frac{1}{t_{n+1}} \int_{t_{n}}^{t_{n+1}}\left(T(s) z_{n}^{t_{n+1}} T(s) z_{n} d s \|\right. \\
= & \| \frac{1}{t_{n+1}} \int_{0}^{t_{n+1}}\left(T(s) z_{n+1}-T(s) z_{n}\right) d s \\
& +(s) p) d s \|
\end{aligned}
$$

It follows from Lemma 3 that

$$
\left\|z_{n+1}-z_{n}\right\| \leq\left\|y_{n+1}-y_{n}\right\|+\frac{\left|r_{n+1}-r_{n}\right|}{r_{n+1}}\left\|z_{n+1}-y_{n+1}\right\| .
$$

Hence,

$$
\begin{aligned}
\| \sigma_{n+1} & -\sigma_{n} \| \\
& \leq\left\|y_{n+1}-y_{n}\right\|+\frac{\left|r_{n+1}-r_{n}\right|}{r_{n+1}}\left\|z_{n+1}-y_{n+1}\right\| \\
& +\frac{2\left|t_{n+1}-t_{n}\right|}{t_{n+1}}\left\|z_{n}-p\right\| \\
& \leq\left\|\alpha_{n+1} u+\left(1-\alpha_{n+1}\right) x_{n+1}-\alpha_{n} u-\left(1-\alpha_{n}\right) x_{n}\right\|
\end{aligned}
$$




$$
\begin{aligned}
& +\frac{\left|r_{n+1}-r_{n}\right|}{r_{n+1}}\left\|z_{n+1}-y_{n+1}\right\|+\frac{2\left|t_{n+1}-t_{n}\right|}{t_{n+1}}\left\|z_{n}-p\right\| \\
\leq & \left\|x_{n+1}-x_{n}\right\|+\alpha_{n+1}\left(\|u\|+\left\|x_{n+1}\right\|\right)+\alpha_{n}\left(\|u\|+\left\|x_{n}\right\|\right) \\
& +\frac{\left|r_{n+1}-r_{n}\right|}{c}\left\|z_{n+1}-y_{n+1}\right\|+\frac{2\left|t_{n+1}-t_{n}\right|}{t_{n+1}}\left\|z_{n}-p\right\| .
\end{aligned}
$$

This implies that

$$
\limsup _{n \rightarrow \infty}\left(\left\|\sigma_{n+1}-\sigma_{n}\right\|-\left\|x_{n+1}-x_{n}\right\|\right) \leq 0 .
$$

It follows from Lemma 5 that $\lim _{n \rightarrow \infty}\left\|\sigma_{n}-x_{n}\right\|=0$. Thus,

$$
\lim _{n \rightarrow \infty}\left\|x_{n+1}-x_{n}\right\|=\lim _{n \rightarrow \infty} \beta_{n}\left\|\sigma_{n}-x_{n}\right\|=0 .
$$

For any $p \in \Omega$, we have

$$
\begin{aligned}
\left\|z_{n}-p\right\|^{2} & =\left\|T_{r_{n}} y_{n}-T_{r_{n}} p\right\|^{2} \\
& \leq\left\langle y_{n}-p, z_{n}-p\right\rangle \\
& =\frac{1}{2}\left[\left\|y_{n}-p\right\|^{2}+\left\|z_{n}-p\right\|^{2}-\left\|z_{n}-y_{n}\right\|^{2}\right] .
\end{aligned}
$$

Thus

$$
\left\|z_{n}-p\right\|^{2} \leq\left\|y_{n}-p\right\|^{2}-\left\|z_{n}-y_{n}\right\|^{2} .
$$

From the convexity of $\|\cdot\|^{2}$, it follows that

$$
\begin{aligned}
& \| x_{n+1}- p \|^{2} \\
&=\left\|\left(1-\beta_{n}\right)\left(x_{n}-p\right)+\beta_{n}\left(\frac{1}{t_{n}} \int_{0}^{t_{n}} T(s) z_{n} d s-p\right)\right\|^{2} \\
& \leq\left(1-\beta_{n}\right)\left\|x_{n}-p\right\|^{2} \\
&+\beta_{n}\left\|\frac{1}{t_{n}} \int_{0}^{t_{n}}\left(T(s) z_{n}-T(s) p\right) d s\right\|^{2} \\
& \leq\left(1-\beta_{n}\right)\left\|x_{n}-p\right\|^{2}+\beta_{n}\left\|z_{n}-p\right\|^{2} \\
& \leq\left(1-\beta_{n}\right)\left\|x_{n}-p\right\|^{2}+\beta_{n}\left[\left\|y_{n}-p\right\|^{2}-\left\|z_{n}-y_{n}\right\|^{2}\right] \\
& \leq\left(1-\beta_{n}\right)\left\|x_{n}-p\right\|^{2}+\beta_{n}\left[\left\|\alpha_{n} u+\left(1-\alpha_{n}\right) x_{n}-p\right\|^{2}\right. \\
&\left.\quad-\left\|z_{n}-y_{n}\right\|^{2}\right] \\
& \leq\left(1-\beta_{n}\right)\left\|x_{n}-p\right\|^{2}+\beta_{n}\left[\left(1-\alpha_{n}\right)\left\|x_{n}-p\right\|^{2}\right. \\
&\left.\quad+\alpha_{n}\|u-p\|^{2}-\left\|z_{n}-y_{n}\right\|^{2}\right] .
\end{aligned}
$$

Hence

$$
\begin{aligned}
\beta_{n}\left\|z_{n}-y_{n}\right\|^{2} \leq & \left\|x_{n}-p\right\|^{2}-\left\|x_{n+1}-p\right\|^{2}+\alpha_{n} \beta_{n}\|u-p\|^{2} \\
& \leq\left\|x_{n}-x_{n+1}\right\|\left(\left\|x_{n}-p\right\|+\left\|x_{n+1}-p\right\|\right) \\
& +\alpha_{n} \beta_{n}\|u-p\|^{2} .
\end{aligned}
$$

Since $\lim _{n \rightarrow \infty}\left\|x_{n+1}-x_{n}\right\|=0$ and $\lim _{n \rightarrow \infty} \alpha_{n}=0$, one has

$$
\lim _{n \rightarrow \infty}\left\|z_{n}-y_{n}\right\|=0 \text {. }
$$

Observe that

$$
\lim _{n \rightarrow \infty}\left\|y_{n}-x_{n}\right\|=\lim _{n \rightarrow \infty} \alpha_{n}\left\|u-x_{n}\right\|=0 .
$$

As $\left\|z_{n}-x_{n}\right\| \leq\left\|z_{n}-y_{n}\right\|+\left\|y_{n}-x_{n}\right\|$, the following equality holds:

$$
\lim _{n \rightarrow \infty}\left\|z_{n}-x_{n}\right\|=0 .
$$

Now we show that

$$
\lim _{n \rightarrow \infty}\left\|T(s) z_{n}-z_{n}\right\|=0, \quad \forall 0 \leq s<\infty .
$$

In fact, we have

$\left\|T(s) z_{n}-z_{n}\right\|$

$$
\begin{aligned}
=\| T(s) z_{n}-T(s) \frac{1}{t_{n}} \int_{0}^{t_{n}} T(s) z_{n} d s \\
\quad+T(s) \frac{1}{t_{n}} \int_{0}^{t_{n}} T(s) z_{n} d s-\frac{1}{t_{n}} \int_{0}^{t_{n}} T(s) z_{n} d s \\
\quad+\frac{1}{t_{n}} \int_{0}^{t_{n}} T(s) z_{n} d s-z_{n} \| \\
\leq\left\|T(s) z_{n}-T(s) \frac{1}{t_{n}} \int_{0}^{t_{n}} T(s) z_{n} d s\right\| \\
+\left\|T(s) \frac{1}{t_{n}} \int_{0}^{t_{n}} T(s) z_{n} d s-\frac{1}{t_{n}} \int_{0}^{t_{n}} T(s) z_{n} d s\right\| \\
+\left\|\frac{1}{t_{n}} \int_{0}^{t_{n}} T(s) z_{n} d s-z_{n}\right\| \\
\leq 2\left\|\frac{1}{t_{n}} \int_{0}^{t_{n}} T(s) z_{n} d s-z_{n}\right\| \\
+\left\|T(s) \frac{1}{t_{n}} \int_{0}^{t_{n}} T(s) z_{n} d s-\frac{1}{t_{n}} \int_{0}^{t_{n}} T(s) z_{n} d s\right\| .
\end{aligned}
$$

Notice that

$$
\begin{aligned}
& \left\|\frac{1}{t_{n}} \int_{0}^{t_{n}} T(s) z_{n} d s-z_{n}\right\| \\
& \quad \leq\left\|\frac{1}{t_{n}} \int_{0}^{t_{n}} T(s) z_{n} d s-x_{n}\right\|+\left\|x_{n}-z_{n}\right\| \\
& \quad=\frac{1}{\beta_{n}}\left\|x_{n+1}-x_{n}\right\|+\left\|x_{n}-z_{n}\right\| \longrightarrow 0, \text { as } n \longrightarrow \infty .
\end{aligned}
$$

For any $p \in \Omega$, let $G=\left\{x \in C:\|x-p\| \leq \max \left\{\left\|x_{1}-p\right\|, \| u-\right.\right.$ $p \|\}\}$. It is easy to see that $G$ is a bounded closed convex subset and $T(s) G$ is a subset of $G$. Since

$$
\begin{aligned}
\left\|z_{n}-p\right\| & =\left\|T_{r_{n}} y_{n}-p\right\| \\
& \leq\left(1-\alpha_{n}\right)\left\|x_{n}-p\right\|+\alpha_{n}\|u-p\| \\
& \leq \max \left\{\left\|x_{1}-p\right\|,\|u-p\|\right\},
\end{aligned}
$$


the sequence $\left\{z_{n}\right\}$ is contained in $G$. It follows from Lemma 4 that

$$
\lim _{n \rightarrow \infty}\left\|\frac{1}{t_{n}} \int_{0}^{t_{n}} T(s) z_{n} d s-T(s) \frac{1}{t_{n}} \int_{0}^{t_{n}} T(s) z_{n} d s\right\|=0 .
$$

From (29), (30), and (32), the expression (28) is obtained.

Next we prove that

$$
\limsup _{n \rightarrow \infty}\left\langle u-\bar{x}, x_{n}-\bar{x}\right\rangle \leq 0,
$$

where $\bar{x}=P_{\Omega} u$. In order to show this inequality, we can choose a subsequence $\left\{x_{n_{j}}\right\}$ of $\left\{x_{n}\right\}$ such that

$$
\limsup _{n \rightarrow \infty}\left\langle u-\bar{x}, x_{n}-\bar{x}\right\rangle=\lim _{j \rightarrow \infty}\left\langle u-\bar{x}, x_{n_{j}}-\bar{x}\right\rangle .
$$

Due to the boundedness of $\left\{x_{n_{j}}\right\}$, there exists a subsequence $\left\{x_{n_{j_{i}}}\right\}$ of $\left\{x_{n_{j}}\right\}$ such that $x_{n_{j_{i}}} \rightarrow \omega$. Without loss of generality, we assume that $x_{n_{j}} \rightarrow \omega$. From (27), we see that $z_{n_{j}} \rightarrow \omega$. Since $\left\{z_{n_{j}}\right\} \subset C$ and $C$ is closed and convex, we get $\omega \in C$.

We first show that $\omega \in \operatorname{EP}(f)$. By $z_{n}=T_{r_{n}} y_{n}$, we have

$$
f\left(z_{n}, y\right)+\frac{1}{r_{n}}\left\langle y-z_{n}, z_{n}-y_{n}\right\rangle \geq 0, \quad \forall y \in C .
$$

It follows from the monotonicity of $f$ that

$$
\frac{1}{r_{n}}\left\langle y-z_{n}, z_{n}-y_{n}\right\rangle \geq f\left(y, z_{n}\right), \quad \forall y \in C .
$$

Replacing $n$ by $n_{j}$, we obtain

$$
\left\langle y-z_{n_{j}}, \frac{z_{n_{j}}-y_{n_{j}}}{r_{n_{j}}}\right\rangle \geq f\left(y, z_{n_{j}}\right), \quad \forall y \in C .
$$

From (25), (27), and (A4), we have

$$
f(y, \omega) \leq 0, \quad \forall y \in C .
$$

For $0<t \leq 1, y \in C$, set $y_{t}=t y+(1-t) \omega$. We have $y_{t} \in C$ and $f\left(y_{t}, \omega\right) \leq 0$. Hence

$$
0=f\left(y_{t}, y_{t}\right) \leq t f\left(y_{t}, y\right)+(1-t) f\left(y_{t}, \omega\right) \leq t f\left(y_{t}, y\right) .
$$

Dividing by $t$, we see that

$$
f\left(y_{t}, y\right) \geq 0
$$

Letting $t \downarrow 0$ and from (A3), we get

$$
f(\omega, y) \geq 0, \quad \forall y \in C .
$$

That is, $\omega \in \operatorname{EP}(f)$.

Second, we prove that $\omega \in F(\mathcal{S})$. Note that the equality (27) implies that $z_{n_{j}} \rightarrow \omega$. Suppose for contradiction that $\omega \notin$ $F(\mathcal{S})$; that is,

$$
\text { there exists } s_{0}>0 \text { such that } T\left(s_{0}\right) \omega \neq \omega \text {. }
$$

Then from Opial's condition and (28), we obtain

$$
\begin{aligned}
& \liminf _{j \rightarrow \infty}\left\|z_{n_{j}}-T\left(s_{0}\right) \omega\right\| \\
& \quad=\liminf _{j \rightarrow \infty}\left\|z_{n_{j}}-T\left(s_{0}\right) z_{n_{j}}+T\left(s_{0}\right) z_{n_{j}}-T\left(s_{0}\right) \omega\right\| \\
& \quad=\liminf _{j \rightarrow \infty}\left\|T\left(s_{0}\right) z_{n_{j}}-T\left(s_{0}\right) \omega\right\| \\
& \quad \leq \liminf _{j \rightarrow \infty}\left\|z_{n_{j}}-\omega\right\|,
\end{aligned}
$$

which is a contradiction. Therefore, $\omega \in F(\mathcal{S})$. Consequently, one gets $\omega \in \Omega$.

From (34) and the property of metric projection, we have

$$
\begin{aligned}
\limsup _{n \rightarrow \infty}\left\langle u-\bar{x}, x_{n}-\bar{x}\right\rangle & =\lim _{j \rightarrow \infty}\left\langle u-\bar{x}, x_{n_{j}}-\bar{x}\right\rangle \\
& =\langle u-\bar{x}, \omega-\bar{x}\rangle \leq 0 .
\end{aligned}
$$

The inequality (33) arrives.

Finally we show that $x_{n} \rightarrow \bar{x}$. From (11), we have

$$
\begin{aligned}
&\left\|x_{n+1}-\bar{x}\right\|^{2} \\
&=\left\|\left(1-\beta_{n}\right) x_{n}+\beta_{n} \frac{1}{t_{n}} \int_{0}^{t_{n}} T(s) z_{n} d s-\bar{x}\right\|^{2} \\
& \leq\left(1-\beta_{n}\right)\left\|x_{n}-\bar{x}\right\|^{2}+\beta_{n}\left\|z_{n}-\bar{x}\right\|^{2} \\
& \leq\left(1-\beta_{n}\right)\left\|x_{n}-\bar{x}\right\|^{2}+\beta_{n}\left\|y_{n}-\bar{x}\right\|^{2} \\
& \leq\left(1-\alpha_{n} \beta_{n}\right)\left\|x_{n}-\bar{x}\right\|^{2} \\
&+\alpha_{n} \beta_{n}\left[2\left(1-\alpha_{n}\right)\left\langle u-\bar{x}, x_{n}-\bar{x}\right\rangle+\alpha_{n}\|u-\bar{x}\|^{2}\right] .
\end{aligned}
$$

It follows from (33) and Lemma 6 that $\left\{x_{n}\right\}$ converges strongly to $\bar{x}$.

Remark 8. Let $H=\mathbb{R}$ and $C=[0,1]$. Setting $f(x, y)=y^{2}-$ $x^{2}$, we see that $f(x, y)$ satisfies (A1)-(A4). For $0 \leq t<+\infty$, let

$$
T(t) x=\frac{x}{1+t x}, \quad \forall x \in[0,1] .
$$

Thus, it follows that $\mathcal{S}=\{T(t): 0 \leq t<\infty\}$ is a nonexpansive semigroup such that $F(\mathcal{S}) \cap \operatorname{EP}(f)=\{0\}$. If we take

$$
\begin{aligned}
\alpha_{n}=\frac{1}{n+1}, \quad \beta_{1} & =\beta_{2}=\frac{1}{2}, \quad \beta_{n}=\frac{1}{2}-\frac{1}{n}, \quad \forall n \geq 3, \\
r_{n} & \equiv c>0, \quad t_{n}=n,
\end{aligned}
$$

then all assumptions and conditions in Theorem 7 are satisfied.

Remark 9. Taking $u=0$ in Theorem 7 , we obtain the iterative method for minimum-norm solution of an equilibrium problem and a nonexpansive semigroup. 
As a direct consequence of Theorem 7, we obtain the following corollary.

Corollary 10. Let $C$ be a nonempty closed convex subset of a real Hilbert space $H$, and assume that $\mathcal{S}=\{T(t): 0 \leq t<\infty\}$ is a nonexpansive semigroup on $C$ such that $F(\mathcal{S}) \neq \emptyset$. Let $\left\{\alpha_{n}\right\}$ and $\left\{\beta_{n}\right\}$ be real sequences in $(0,1)$, and let $\left\{x_{n}\right\}$ and $\left\{z_{n}\right\}$ be generated by

$$
\begin{gathered}
x_{1} \in C \text { chosen arbitrarily, } \\
z_{n}=P_{C}\left[\left(1-\alpha_{n}\right) x_{n}\right], \\
x_{n+1}=\left(1-\beta_{n}\right) x_{n}+\beta_{n} \frac{1}{t_{n}} \int_{0}^{t_{n}} T(s) z_{n} d s .
\end{gathered}
$$

Suppose that the following conditions are satisfied:

(1) $\lim _{n \rightarrow \infty} \alpha_{n}=0$ and $\sum_{n=1}^{\infty} \alpha_{n}=\infty$;

(2) $0<\liminf _{n \rightarrow \infty} \beta_{n} \leq \lim \sup _{n \rightarrow \infty} \beta_{n}<1$;

(3) $\left\{t_{n}\right\} \subset(0, \infty), \lim _{n \rightarrow \infty} t_{n}=\infty$, and $\lim _{n \rightarrow \infty}\left(\mid t_{n+1}-\right.$ $\left.t_{n} \mid / t_{n+1}\right)=0$.

Then the sequence $\left\{x_{n}\right\}$ converges strongly to $P_{F(\delta)} 0$.

Proof. Letting $f(x, y)=0$ for all $x, y \in C, r_{n}=1$, and $u=0$ in Theorem 7, we get the result.

Remark 11. Corollary 10 extends the recent results of Zegeye and Shahzad [11, Corollaries 3.2 and 3.3] from finite family of nonexpansive mappings to a nonexpansive semigroup.

\section{A Note on Shehu's Paper "Iterative Method for Fixed Point Problem, Variational Inequality and Generalized Mixed Equilibrium Problems with Applications"}

In 2012, Shehu [10] studied iterative methods for fixed point problem, variational inequality, and generalized mixed equilibrium problem and gave an interesting convergence theorem. However, there is a slight flaw in the proof of the main result (Theorem 3.1 in [10]).

Shehu obtained the following result (for more details, see [10]).

Theorem 12 (see [10]). Let $K$ be a closed convex subset of a real Hilbert space $H$, let $F$ be a bifunction from $K \times K$ satisfying (A1)-(A4), let $\varphi: K \rightarrow \mathbb{R} \cup\{+\infty\}$ be a proper lower semicontinuous and convex function with assumption (B1) or (B2), let $A$ be a $\mu$-Lipschitzian, relaxed $(\lambda, \gamma)$-cocoercive mapping of $K$ into $H$, and let $\psi$ be an $\alpha$-inverse, strongly monotone mapping of $K$ into $H$. Suppose that $T: K \rightarrow K$ is a nonexpansive mapping of $K$ into itself such that $\Omega:=$ $F(T) \cap \operatorname{VI}(K, A) \cap G M E P \neq \emptyset$. Let $\left\{\alpha_{n}\right\}$ and $\left\{\beta_{n}\right\}$ be two real sequences in $(0,1)$ and $\left\{r_{n}\right\},\left\{s_{n}\right\} \subset(0, \infty)$. Let $\left\{x_{n}\right\},\left\{y_{n}\right\}$, and $\left\{u_{n}\right\}$ be generated by $x_{1} \in K$,

$$
\begin{gathered}
y_{n}=P_{K}\left[\left(1-\alpha_{n}\right) x_{n}\right], \\
u_{n}=T_{r_{n}}^{(F, \varphi)}\left(y_{n}-r_{n} \psi y_{n}\right), \\
x_{n+1}=\left(1-\beta_{n}\right) x_{n}+\beta_{n} T P_{K}\left(u_{n}-s_{n} A u_{n}\right) .
\end{gathered}
$$

Suppose that the following conditions are satisfied:

(a) $\lim _{n \rightarrow \infty} \alpha_{n}=0$ and $\sum_{n=1}^{\infty} \alpha_{n}=\infty$;

(b) $0<\lim \inf _{n \rightarrow \infty} \beta_{n} \leq \lim \sup _{n \rightarrow \infty} \beta_{n}<1$;

(c) $0<a \leq s_{n} \leq b<2\left(\gamma-\lambda \mu^{2}\right) / \mu^{2}, \lim _{n \rightarrow \infty}\left|s_{n+1}-s_{n}\right|=0$;

(d) $0<c \leq r_{n} \leq d<2 \alpha, \lim _{n \rightarrow \infty}\left|r_{n+1}-r_{n}\right|=0$.

Then, the sequence $\left\{x_{n}\right\}$ converges strongly to an element of $F(T) \cap V I(K, A) \cap G M E P$.

This theorem is proved in [10] by the following steps.

Step 1. The sequence $\left\{x_{n}\right\}$ is bounded.

Step 2. The following equalities hold:

$$
\begin{aligned}
\lim _{n \rightarrow \infty}\left\|A u_{n}-A x^{*}\right\|=0, \quad \lim _{n \rightarrow \infty}\left\|\psi y_{n}-\psi x^{*}\right\| & =0, \\
\forall x^{*} & \in \Omega .
\end{aligned}
$$

Step 3. If $\omega$ is a weak limit of $\left\{x_{n_{j}}\right\}$ which is a subsequence of $\left\{x_{n}\right\}$, then $\omega \in \Omega$.

Step 4. The sequence $\left\{x_{n}\right\}$ converges strongly to $\omega$.

In Step 4, in order to show that the sequence $\left\{x_{n}\right\}$ converges strongly to $\omega$, the author shows the inequality $\lim \sup _{n \rightarrow \infty}\left\langle-\omega, x_{n}-\omega\right\rangle \leq 0$ by defining a mapping $\phi$ : $H \rightarrow R$ as follows: $\phi(x)=\mu_{n}\left\|x_{n}-x\right\|^{2}$, where $\mu$ is a Banach limit. It is proved that the set $K^{*}=\{x \in H: \phi(x)=$ $\left.\min _{u \in H} \phi(u)\right\} \neq \emptyset$ and $K^{*} \cap F(T) \neq \emptyset$. An element of $K^{*} \cap F(T)$ is taken arbitrarily and is denoted by $\omega$. Of course, the element $\omega$ is not necessarily the weak sequential cluster point of $\left\{x_{n}\right\}$. However, in Step 3, the symbol $\omega$ stands for the weak limit of $\left\{x_{n_{j}}\right\}$ which is a subsequence of $\left\{x_{n}\right\}$. In the sequel, the author obtains

$$
\left\|x_{n+1}-\omega\right\|^{2} \leq\left(1-\beta_{n}\right)\left\|x_{n}-\omega\right\|^{2}+\beta_{n}\left\|y_{n}-\omega\right\|^{2} .
$$

The meaning of the element $\omega$ in (51) is ambiguous. It is difficult to ensure consistency.

Now, we perfect and simplify the proof of Step 4. According to the equality in Step $2, \lim _{n \rightarrow \infty}\left\|A u_{n}-A x^{*}\right\|=0$, for all $x^{*} \in \Omega$, we see that the set $\left\{A x^{*}: x^{*} \in \Omega\right\}$ contains only one element. Since $A$ is a relaxed $(\lambda, \gamma)$-cocoercive mapping of $K$ into $H$, that is, there exist $\lambda, \gamma>0$ such that

$$
\begin{array}{r}
\langle A x-A y, x-y\rangle \geq-\lambda\|A x-A y\|^{2}+\gamma\|x-y\|^{2}, \\
\forall x, y \in K,
\end{array}
$$


it follows that the mapping $A$ is one-to-one. Therefore, the set $\Omega$ is a singleton. By Step 3, the sequence $\left\{x_{n}\right\}$ possesses only one weak sequential cluster point. It follows from Lemma 2.38 in [16] that $\left\{x_{n}\right\}$ converges weakly to $\omega$ and so

$$
\begin{aligned}
\| x_{n+1}- & \omega \|^{2} \\
\leq & \left(1-\beta_{n}\right)\left\|x_{n}-\omega\right\|^{2}+\beta_{n}\left\|y_{n}-\omega\right\|^{2} \\
\leq & \left(1-\beta_{n}\right)\left\|x_{n}-\omega\right\|^{2}+\beta_{n}\left\|\left(1-\alpha_{n}\right) x_{n}-\omega\right\|^{2} \\
\leq & \left(1-\beta_{n}\right)\left\|x_{n}-\omega\right\|^{2} \\
& +\beta_{n}\left[\left(1-\alpha_{n}\right)\left\|x_{n}-\omega\right\|^{2}\right. \\
& \left.\quad+2 \alpha_{n}\left(1-\alpha_{n}\right)\left\langle-\omega, x_{n}-\omega\right\rangle+\alpha_{n}^{2}\|\omega\|^{2}\right] \\
\leq & \left(1-\alpha_{n} \beta_{n}\right)\left\|x_{n}-\omega\right\|^{2} \\
& +\alpha_{n} \beta_{n}\left[2\left(1-\alpha_{n}\right)\left\langle-\omega, x_{n}-\omega\right\rangle+\alpha_{n}\|\omega\|^{2}\right] .
\end{aligned}
$$

Since $\left\{x_{n}\right\}$ converges weakly to $\omega$, it follows from Lemma 2.2 in [10] or Lemma 6 in this paper that $\left\{x_{n}\right\}$ converges strongly to $\omega \in \Omega$.

\section{Conflict of Interests}

The authors declare that there is no conflict of interests.

\section{Acknowledgment}

The authors would like to thank referees and editors for their valuable comments and suggestions.

\section{References}

[1] E. Blum and W. Oettli, "From optimization and variational inequalities to equilibrium problems," The Mathematics Student, vol. 63, no. 1-4, pp. 123-145, 1994.

[2] P. L. Combettes and S. A. Hirstoaga, "Equilibrium programming in Hilbert spaces," Journal of Nonlinear and Convex Analysis, vol. 6, no. 1, pp. 117-136, 2005.

[3] Y. Liu, "A general iterative method for equilibrium problems and strict pseudo-contractions in Hilbert spaces," Nonlinear Analysis: Theory, Methods \& Applications, vol. 71, no. 10, pp. 4852-4861, 2009.

[4] S. Takahashi and W. Takahashi, "Viscosity approximation methods for equilibrium problems and fixed point problems in Hilbert spaces," Journal of Mathematical Analysis and Applications, vol. 331, no. 1, pp. 506-515, 2007.

[5] D.-N. Qu and C.-Z. Cheng, "A strong convergence theorem on solving common solutions for generalized equilibrium problems and fixed-point problems in Banach space," Fixed Point Theory and Applications, vol. 2011, article 17, 2011.

[6] R. D. Chen, X. L. Shen, and S. J. Cui, "Weak and strong convergence theorems for equilibrium problems and countable strict pseudocontractions mappings in Hilbert space," Journal of Inequalities and Applications, vol. 2010, Article ID 474813, 11 pages, 2010.
[7] C. Jaiboon and P. Kumam, "Strong convergence for generalized equilibrium problems, fixed point problems and relaxed cocoercive variational inequalities," Journal of Inequalities and Applications, vol. 2010, Article ID 728028, 43 pages, 2010.

[8] K. Nakajo and W. Takahashi, "Strong convergence theorems for nonexpansive mappings and nonexpansive semigroups," Journal of Mathematical Analysis and Applications, vol. 279, no. 2, pp. 372-379, 2003.

[9] N. Buong and N. D. Duong, "Weak convergence theorem for an equilibrium problem and a nonexpansive semigroup in Hilbert spaces," International Mathematical Forum, vol. 5, no. 53-56, pp. 2775-2786, 2010.

[10] Y. Shehu, "Iterative method for fixed point problem, variational inequality and generalized mixed equilibrium problems with applications," Journal of Global Optimization, vol. 52, no. 1, pp. 57-77, 2012.

[11] H. Zegeye and N. Shahzad, "Approximation of the common minimum-norm fixed point of a finite family of asymptotically nonexpansive mappings," Fixed Point Theory and Applications, vol. 2013, article 1, 2013.

[12] F. Cianciaruso, G. Marino, and L. Muglia, "Iterative methods for equilibrium and fixed point problems for nonexpansive semigroups in Hilbert spaces," Journal of Optimization Theory and Applications, vol. 146, no. 2, pp. 491-509, 2010.

[13] T. Shimizu and W. Takahashi, "Strong convergence to common fixed points of families of nonexpansive mappings," Journal of Mathematical Analysis and Applications, vol. 211, no. 1, pp. 7183, 1997.

[14] T. Suzuki, "Strong convergence theorems for infinite families of nonexpansive mappings in general Banach spaces," Fixed Point Theory and Applications, vol. 2005, Article ID 685918, 2005.

[15] H.-K. Xu, "Another control condition in an iterative method for nonexpansive mappings," Bulletin of the Australian Mathematical Society, vol. 65, no. 1, pp. 109-113, 2002.

[16] H. H. Bauschke and P. L. Combettes, Convex Analysis and Monotone Operator Theory in Hilbert Spaces, Springer, New York, NY, USA, 2011. 


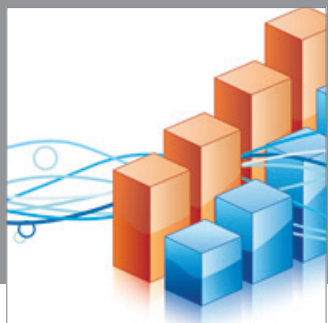

Advances in

Operations Research

mansans

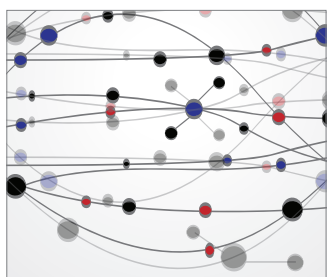

The Scientific World Journal
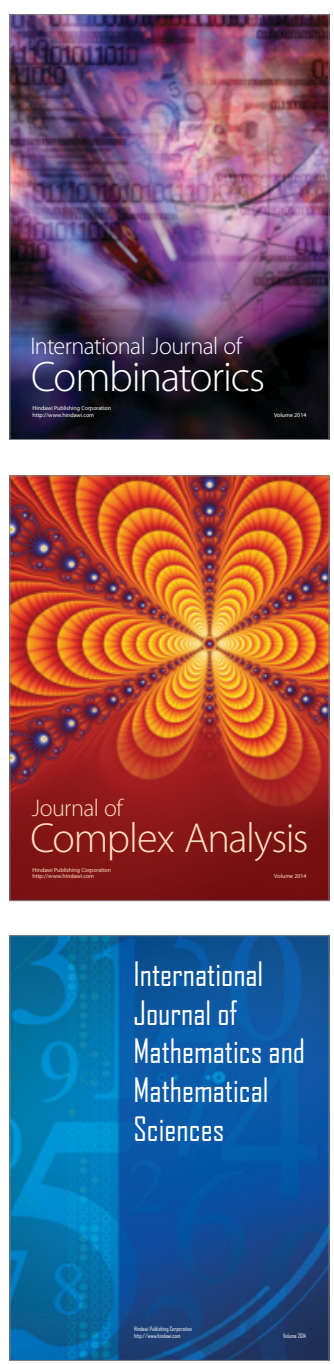
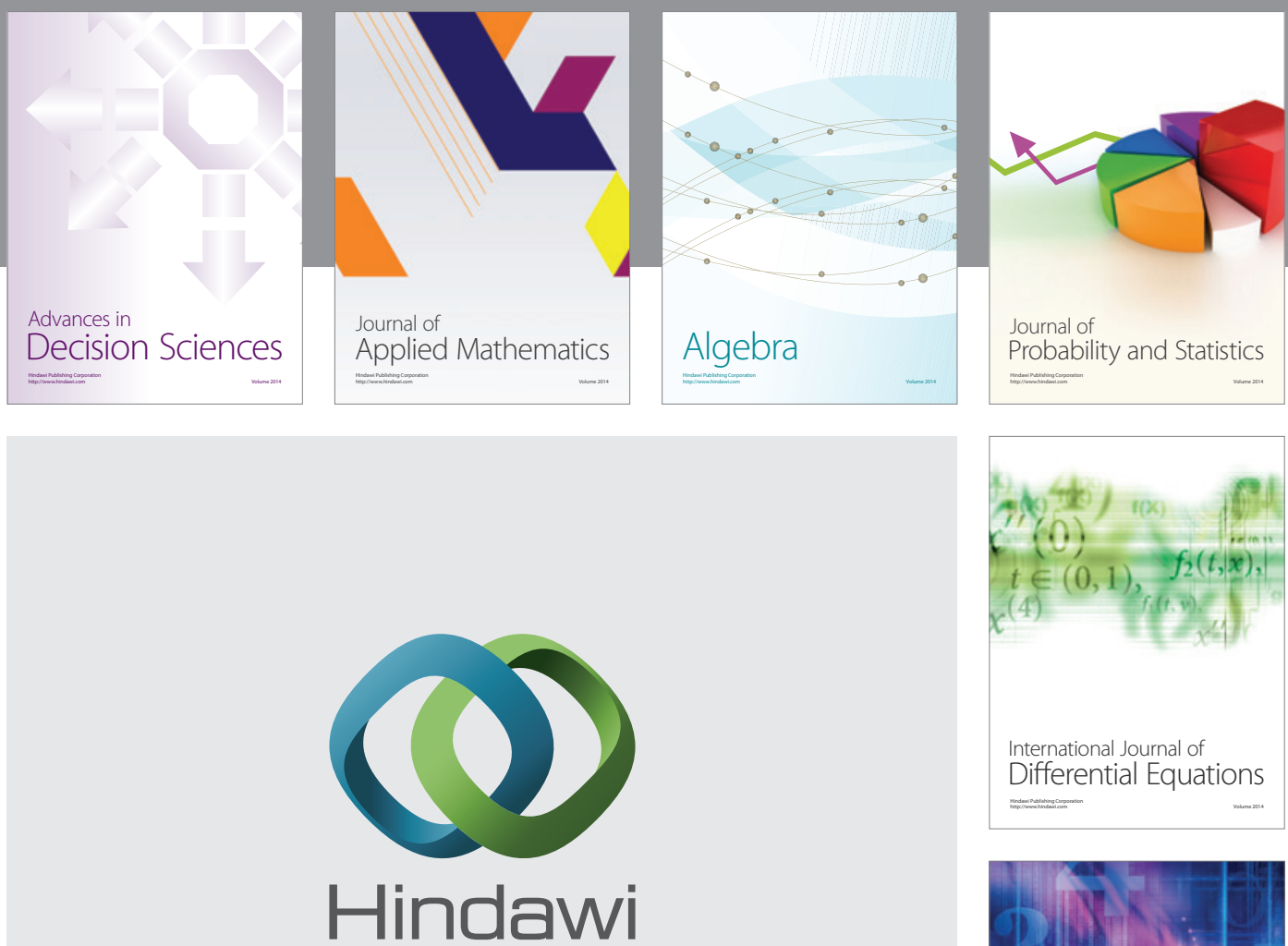

Submit your manuscripts at http://www.hindawi.com
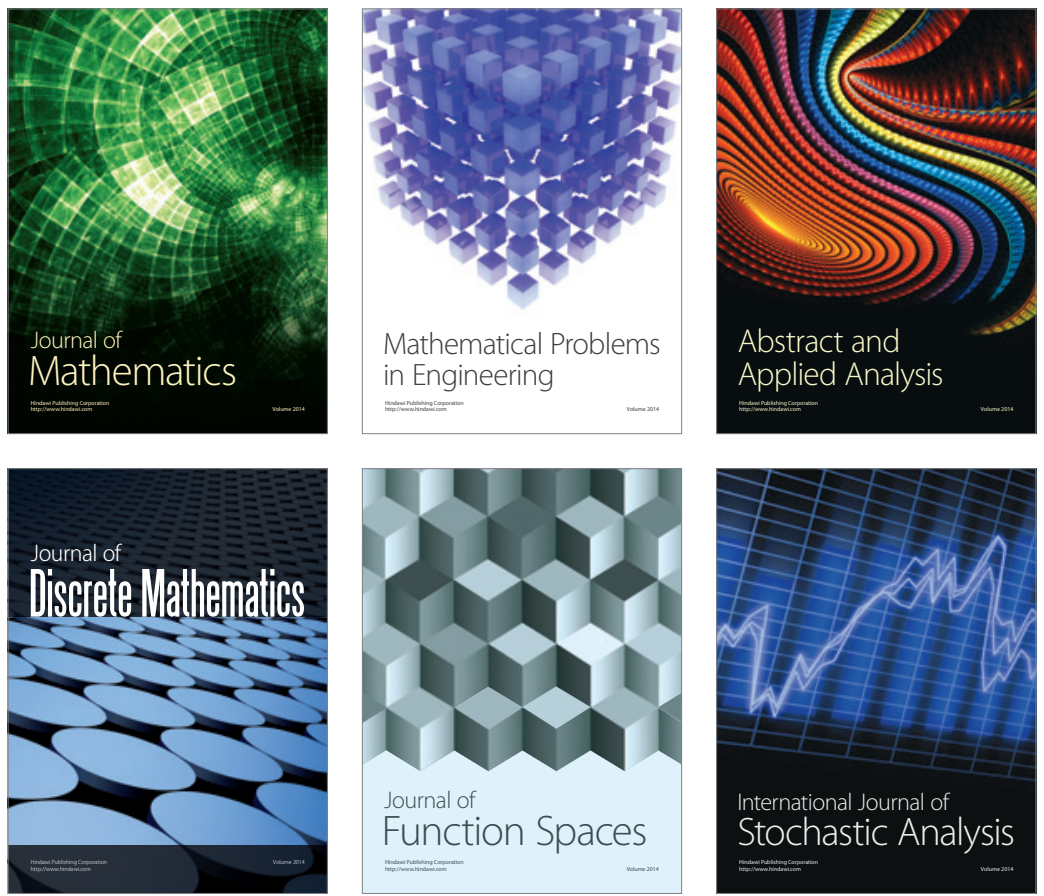

Journal of

Function Spaces

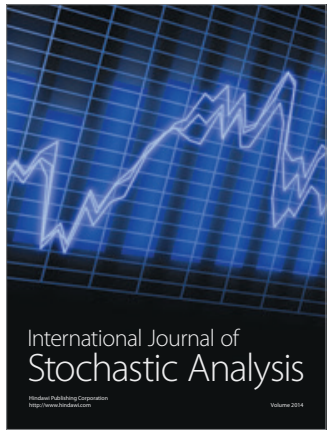

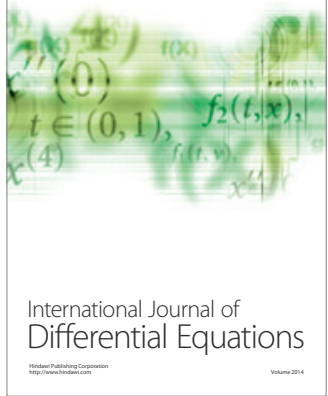
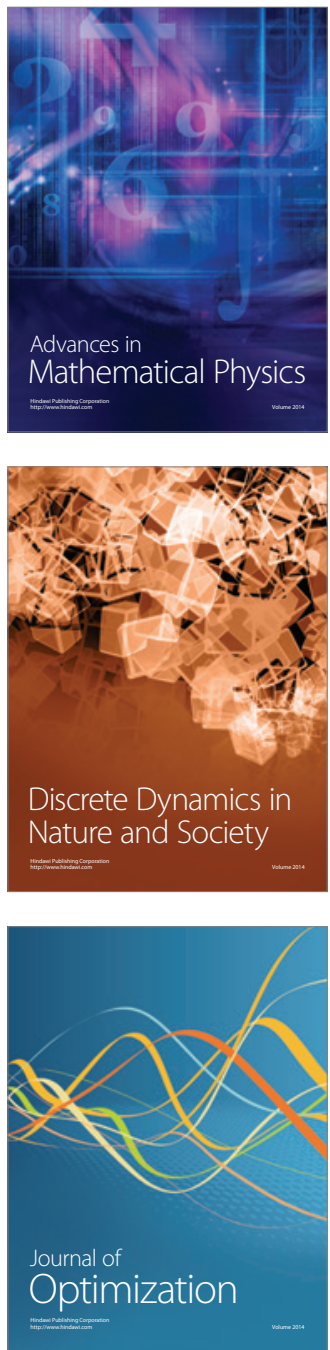